$\Phi=5$

\title{
Sexual health knowledge among secondary school students in Morogoro, Tanzania: half full or full empty?
}

\author{
Gloria Kaale ${ }^{1}$, Mikidadi Muhanga ${ }^{2} *$ \\ ${ }^{1}$ Department of Development Studies, Sokoine University of Agriculture, P.o.Box 3024, Fax: +25523 2604646, Morogoro-Tanzania \\ 2 Department of Development Studies, Sokoine University of Agriculture, P.o.Box 3024, Fax: +255 23 2604646, Mobile: $+255715 / 754$ \\ 292528, Morogoro-Tanzania \\ *Corresponding author E-mail: mikidadi@suanet.ac.tz
}

\begin{abstract}
Background: Sexual health knowledge (SHK) is very crucial as the world is facing HIV/AIDS tragedy, increased cases of sexually transmitted infections (STIs) and unsafe abortions among adolescents. It is obvious that knowledge is an important prevention factor for any disease.

Objectives: The study was conducted to assess knowledge and attitude on sexual health among secondary school students in Morogoro Municipality. Specifically the study (I: (i) examined students' knowledge and attitude on sexual transmitted infections, (ii) analyzed student's awareness on early pregnancy prevention, and; (iii) determined students' knowledge on issues related to puberty.

Methods: The study involved 75 respondents from five secondary schools and 13 key informants through purposive sampling and simple random sampling techniques. Data were collected using a structured questionnaire. Data collected were analyzed using Statistical Package for Social Science (SPSS) ver.12.

Results: Findings revealed that $79.8 \%$ of the respondents had knowledge on sexually transmitted infections, $86.5 \%$ were aware of methods of controlling early pregnancies; $83.9 \%$ have never used protective gears during sexual intercourses, and $54.7 \%$ did not understand a menstruation cycle.

Conclusion: The study recommended for provision of sexual health knowledge to students to reduce incidences of early pregnancies and sexually transmitted infections; likewise on the need to use protective gears during sexual intercourses. Knowledge concerning sexual health is vital for all particularly for adolescents, as they are vulnerable to adopt negative behaviors if not guided properly and at the right age.
\end{abstract}

Keywords: Sexual Health; Knowledge; Attitudes; Youth; Secondary School Students; Tanzania.

\section{Introduction}

\subsection{Background information and problem statement}

It is reported by UNAIDS (2008) that more than ten million young people globally are living with Human Immuno Virus (HIV), twothirds of whom live in sub-Saharan Africa in which new HIV infections are concentrated among young people, with roughly 45 per cent of all new infections occurring among those aged 15 to 24 years. Each year at least 111 million new cases of curable Sexually Transmitted Infections (STIs) occur among young people aged between 10 and 24, up to 4.4 million girls aged 15 to 19 years seek abortions, the majority of, which are unsafe and 10 per cent of births worldwide are to teenage mothers, who experience higher rates of maternal mortality than older women (IPPF, 2006). Tanzania is one of the developing countries where HIV/AIDS, early pregnancies and school dropouts have been affecting youth in general and secondary school students at large.

Sexual health knowledge (SHK) is vital in that regard as it can reduce early pregnancies, unsafe abortions, school dropouts due to early pregnancies and spread of HIV/AIDS plus STIs among secondary school students. In that context, SHK is therefore, very important for an education sector to perform. Sexual health education provides students with age-appropriate, culturally relevant and scientifically accurate information. This will enable students to acquire opportunities to explore their attitudes and values, and practice needed to make informed decisions about their sexual lives (Glasier et al., 2006; Chacko et al., 2007; Herman et al., 2013). Health knowledge can lead to enhancement of health literacy. Health literacy is a very important aspect towards attaining optimal health (Muhanga and Malungo, 2017a).

According to the Centre for Reproductive Rights (2008), international human rights standards, as articulated by United Nations (UN) governing bodies and other international organizations, require that governments guarantee the rights of young people to health, life, education and non-discrimination, through comprehensive sexuality education. The 1994 International Conference on Population and Development (ICPD) in Cairo and the 1995 Fourth World Conference on Women in Beijing emphasize the obligations in international law for states to provide sexuality education in primary and secondary schools (UNESCO, 2009). A variety of international authorities, such as UN Treaty Monitoring Committees, have also set standards on topics that should be included, and solidly support that sexuality education programmes in schools must be comprehensive, covering topics of pregnancy, unsafe abortion, the prevention of HIV/AIDS and STIs, family planning and contraception (UNAIDS, 2006).

The primary goal of sexuality education is that children and young people are equipped with the knowledge, skills and values to make 
responsible choices about their sexual and social relationships in a world affected by HIV and AIDS (UNAIDS, 2006; UNESCO, 2009). The knowledge is even important in HIV prevention, unintended pregnancy, coercive or abusive sexual activity and achieving Universal Access targets for prevention, treatment, care and support (UNAIDS, 2006). Effective programmes can reduce misinformation, increase knowledge, clarify and solidify positive values and attitudes, increase skills, improve perceptions about peer group norms, increase communication with parents or other trusted adults, delay the debut of sexual intercourse, reduce the frequency of unprotected sexual activity, reduce the number of sexual partners and increase the use of protection against pregnancy and STIs during sexual intercourse (UNESCO, 2009).

It is reported by UNAIDS, (2006) that many young people still lack accurate, complete information on how to avoid exposure to HIV. On top of that, UNAIDS (2007) reported that at least half of students around the world did not receive any school-based HIV education. The youth approach adulthood faced with conflicting and confusing messages about sexuality and gender. This is often exacerbated by embarrassment, silence, and disapproval of open discussion about sexual matters by adults, including parents and teachers, at the very time when it is most needed (UNAIDS, 2006) In Tanzania, the number of enrolment in secondary schools has increased; however, there are a number of challenges and one of them being early pregnancies. Furthermore, statistics on sexual transmitted diseases (STDs) show no sign of abating; the everincreasing number of STDs and deaths due to HIV/AIDS are common now. As time goes against the trend of STDs is becoming a big problem among the youth (Klepp, 1994).

The problem of knowledge on sexual health among youth in Tanzania still persists to a larger extent in which there are worse statistics, which verify the danger of the problem. For instance, about 2.2 million adults and children were estimated to have been infected with STDs (Ikamba, 2003). Also it is approximated that $17 \%$ of children under 15 years age in Tanzania had been infection by STDs and about $50 \%$ of the STDs occur before the age of 29 years (Ikamba, 2003). Through a survey which was conducted among youth in both primary and secondary schools, it was revealed that $62 \%$ males and $35 \%$ females were at risk of acquiring STDs, for the case of pupils in Dar Es Salaam also $80 \%$ male and $25 \%$ female secondary school students were predisposed or in danger to acquire STDs (Leshabari, 1988)

Similar survey conducted by Kessy (1996), exposed the reasons which actually contributing to the STDs like failure of youth to practice safe sex, also lack of cash and employment opportunities among youth who in some ways push them to engage in sexual intercourse. For instance, survey depicted that $54 \%$ of the interviewed students aged between 11 and 19 years were at risk of contracting STDs this was the case of primary schools in Dar es saalam (Kessy, 1996). Sexual health in Tanzania is still considered as taboo for both teachers and parents in sitting together with their children and discuss about wellbeing that could help to reduce a serious problem of STDs. Religions also contribute to the problem (MOA, 1994).

One of the problems facing secondary education sector in Tanzania is students' pregnancy. Morogoro, Mbeya and Tanga regions are leading with high rates of school dropouts and girls pregnancies in Tanzania. (Abubakar, 2009). Many young Tanzanians are engaging in premarital sex, with teenage motherhood standing at 30 percent (URT, 2005). Also, statistics from the Ministry of Education and Vocational Training indicated that 11600 girls did not complete secondary due to pregnancy within the period of five years (2004-2008) (Mwananzila, 2009). Furthermore, Masatu et al., (2009) revealed that $32 \%$ of secondary school students are sexually active. The prevalence of STDs among secondary school students has also increased over the past few decades. Tanzania has inadequate programmes that address reproductive health needs for specific population groups, especially adolescents and elderly people. As a result, they lack access to correct information and services (URT, 2006). It is against this background that this study was conducted to assess SHK and attitudes among secondary schools in Morogoro Municipality.

\section{Materials and methods}

\subsection{Study location and rationale for its choice}

This study was conducted in four secondary schools namely, Morogoro Secondary School, Forest Hill Secondary School, Jabal Hira Muslim Secondary School and Bigwa Sisters Secondary School located in Morogoro Municipality. These schools represent different characteristics of secondary schools in Morogoro Municipality as they include those owned by religious institutions, private organizations, and the government, based in the urban setting. Moreover, these schools are located within a region where HIV/AIDS infection rates are high. Morogoro is among the regions in Tanzania that is exposed to many risks of HIV/AIDS and STIS; this is partly due to many visitors who pass through the town to other upcountry regions and countries. Morogoro has the prevalence rate of eight per cent which is above national average, which stands at seven per cent (URT, 2004; TACAIDS, 2005).

\subsection{Study design and data collection}

Cross-sectional research design was used in this study. The population under which sample was drawn involved secondary school students in ordinary and advanced levels within the selected schools in Morogoro Municipality. Purposive sampling technique was used to select secondary schools in this study. Criteria for selection included: nature of ownership and located in urban setting. Simple random sampling was used to obtain respondents within individual schools. Respondents were drawn from a list of names provided by respective school administration. Also, purposive sampling was used to select one key informant from each school, one key informant from district education offices and one from NGO concerned with sexual health education for secondary school students.

The sample size in this study was 75 students from the selected secondary schools in Morogoro Municipality. The sampling size is justified by the fact that a sub-sample of 30 respondents is the bare minimum for studies in which statistical data analysis is to be done regardless of the population size (Bailey, 1994). The choice of this figure is based on the fact that 75 students are sufficient to conduct this study and therefore, representative because of the homogeneous nature of secondary school students. The questionnaire was used to collect primary data from quantitative sources.

\subsection{Data processing and analysis}

Data collected were coded and analyzed using Statistical Package for Social Science (SPSS) version 12. Descriptive statistics such as frequencies and percentages were computed to find the extent of sexual health knowledge among secondary school students. Likert scale was used to gauge attitudes of respondents towards sexual health.

\section{Results and discussion}

\subsection{Socio-demographic characteristics of the respond- ents}

Socio-demographic characteristics of the respondents are found to be very important variables in most behavioural and attitudinal studies (Muhanga and Malungo, 2017b). Some socioeconomic characteristics of the respondents are considered to have influence on knowledge and attitudes on sexual health. In this study, socioeconomic and demographic information of respondents were sought in order to establish the distribution of respondents as well as to establish the background variables to be used in linking the 
socioeconomic variables, knowledge and attitudes on Sexual Health among the secondary school students. This study analyzed sex, age, and family type of the respondents under the sociodemographic characteristics of the respondents.

The findings revealed that $19 \%$ of the respondents interviewed were between 13-15 years of age, whereas $73 \%$ were between 16 - 18 years of age, while $8 \%$ were between 19-21 years of age. In this study $12 \%$ of interviewees were male students and $88 \%$ were female students. The results further revealed that $60 \%$ of the respondents live with both parents, whereas $20 \%$ live with single parents and $20 \%$ do not live with parents.

\subsection{Knowledge on stis by secondary school students in morogoro municipality}

The study found that students have knowledge on STIs as they seem to understand the causes of STIs; whereby $76 \%$ identified unsafe sex, $(1.3 \%)$ body immune deficiency and dirtiness or unhygienic conditions $(2.7 \%)$. The remaining few $(1.3 \%)$ have been found to have knowledge on STIs as they seem to understand the effects. The results indicate that only $18.7 \%$ of the respondents do not have knowledge on STIs. The results are supported by a study by UNAIDS (2006) which found that many young people still lack accurate, complete information on how to avoid exposure to STIs. The details are presented in Fig. 1.

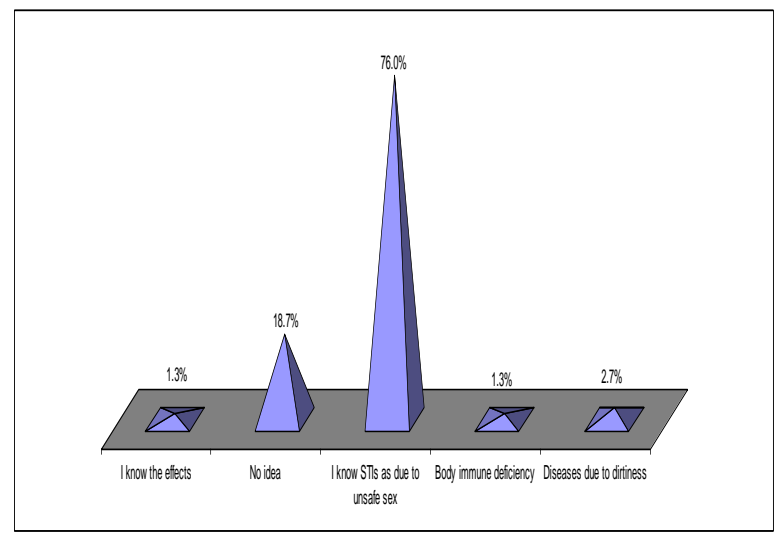

Fig. 1: Students Knowledge on Stis.

\subsection{Students' knowledge on stis by family type}

The results show that $56 \%$ of the respondents who live with both parents identified the cause of STIs as unsafe sex, $2.6 \%$ said STIs are due to dirtiness (unhygienic condition) and sharing towels whereas $1.3 \%$ identified body immune deficiency as a cause and $16 \%$ had no idea. Also $16 \%$ of the respondents who live with a single parent identified the cause of STIs as unsafe sex whereas $1.3 \%$ had no idea. Furthermore, $4 \%$ of the respondents who do not live with parents identified the cause of STIs as unsafe sex and $1.3 \%$ had no idea.

Other studies (Manlove, 1997; Botting et al., 1998; Bonell et al., 2006) document the influence of family type and parenting behaviours on teenage sexual behaviour and knowledge. The details are presented in Table 1.

\subsection{Students' awareness on STIs}

Figure 2 shows how students responded when subjected to statements measuring awareness on STIs. The results revealed that $30.7 \%$ of the students agreed that condoms can prevent STIs, whereas $10.7 \%$ of the students did not agree to the statement. Furthermore, $60 \%$ of the respondents strongly disagreed to the statement that STIs can not affect reproductive health, whereas $2.7 \%$ agreed to the statement. Also, $30.7 \%$ of the students disagreed to the statement that STIs can only be transmitted through sexual conduct and $14.7 \%$ of the students strongly agreed. The results also indicated that $49.3 \%$ of the respondents strongly disagreed to the statement that STIs can be treated and $2.7 \%$ of the respondents strongly agreed to the statement. Also, $33.3 \%$ of the respondents agreed to the statement that people with STIs are more likely to get HIV/AIDS and $6.7 \%$ disagreed to the statement. Generally the results indicate that respondents are aware of STIs with exception of the few who appeared not to be aware. Lack of awareness to others indicates inadequate programmes that address reproductive health needs such as on STIs for specific population groups especially adolescents; this situation is also reported by other studies (UNAIDS, 2006; URT, 2006; UNAIDS, 2007; AlQuaiz, 2013) which are claiming that a significant portion of students around the world did not receive any school-based STIs education, hence many young people still lack accurate, complete information on how to avoid exposure to STIs.

Table 1: Students Knowledge on STIS by Family Type

\begin{tabular}{lllll}
\hline Knowledge on STIs & \multicolumn{4}{l}{ Family type of the respondents } \\
& $\begin{array}{l}\text { Single } \\
\text { parent }\end{array}$ & $\begin{array}{l}\text { Both } \\
\text { parents }\end{array}$ & $\begin{array}{l}\text { Do not } \\
\text { leave with } \\
\text { parents }\end{array}$ & Total \\
\hline $\begin{array}{l}\text { Those knowing the effects } \\
\text { No idea on STIs }\end{array}$ & 1 & 0 & 0 & 1 \\
$\begin{array}{l}\text { know unsafe sex as a cause of } \\
\text { STIs }\end{array}$ & 12 & 12 & 1 & 14 \\
$\begin{array}{l}\text { Body immune deficiency as a } \\
\text { cause of STIs }\end{array}$ & 0 & 42 & 3 & 57 \\
$\begin{array}{l}\text { Diseases due to dirtiness and } \\
\text { sharing towels }\end{array}$ & 0 & 2 & 0 & 1 \\
\begin{tabular}{l} 
Total \\
\hline
\end{tabular} & 14 & 57 & 4 & 75 \\
\hline
\end{tabular}

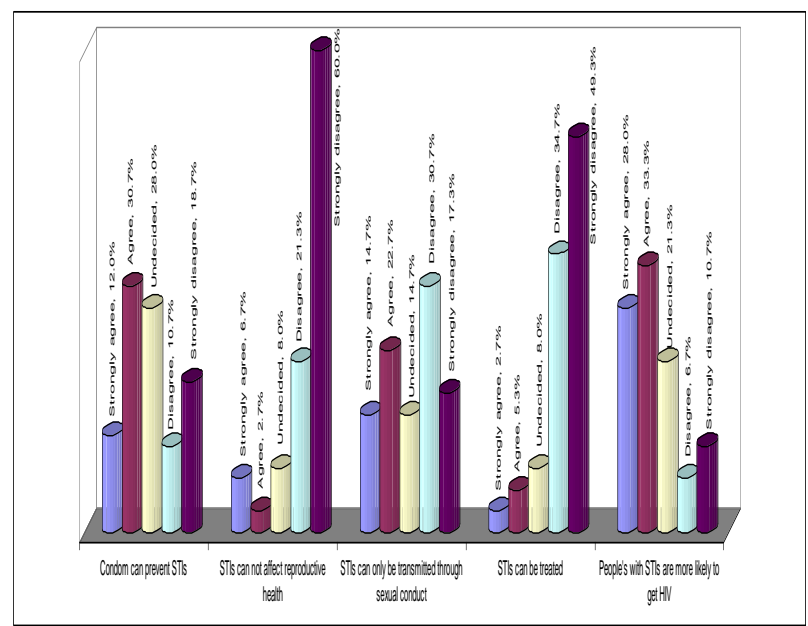

Fig. 2: General Students' Awareness on Stis.

\subsection{Students' awareness on the symptoms of STIs}

The results further revealed that $27.5 \%$ of the respondents were not aware of STIs symptoms whereas the majority $(72.5 \%)$ of the respondents were aware of the symptoms as presented in Fig. 3. It was revealed that for those who were aware of the symptoms, identified loss of weight, urinating blood, skin infections, pain during urinating, urinating pus, sores on reproductive organs and emaciation. 


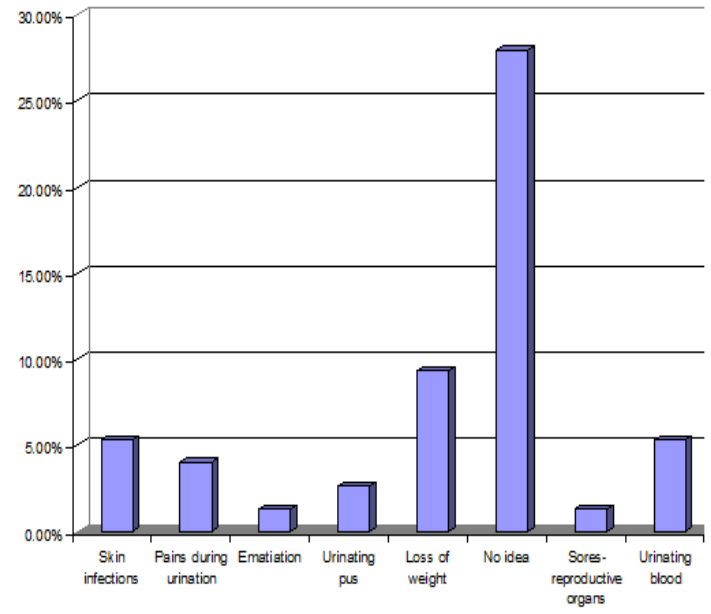

Fig. 3: Identified Symptoms of Stis.

\subsection{Students awareness on the effects of STIs}

The results further revealed that $18.7 \%$ of the respondents were not aware of STIs effects and the remaining $81.3 \%$ of the respondents appeared to be aware of the effects of STIs (Figure 4). Also, $38.7 \%$, of those who were aware identified destruction of reproductive system, followed by death $17.3 \%$, and $10.7 \%$ identified sterility as the effect of STIs. The remaining few identified reduced body immune system, loss of weight, acquiring HIV, abandonment by parents and psychological effects.

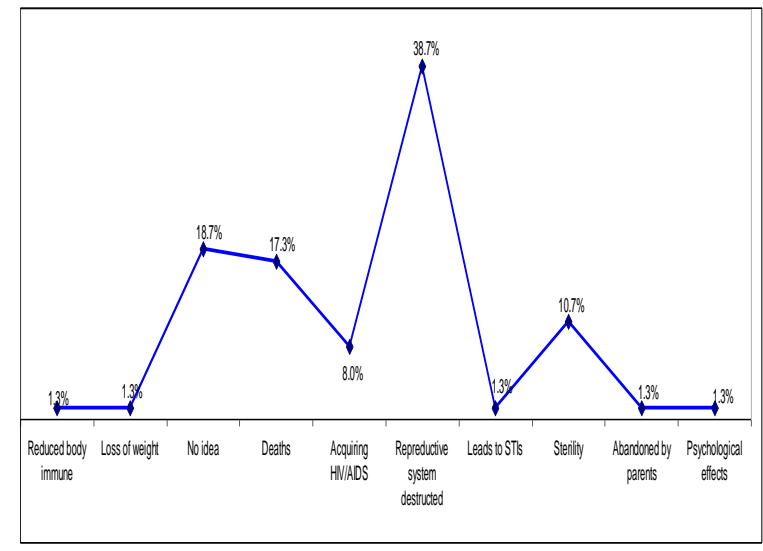

Fig. 4: Students Awareness on the Effects of Stis.

\subsection{Students awareness on STIs prevention}

Figure 5 shows that $16 \%$ of the respondents were not aware of STIs prevention whereas the remaining majority (84\%) were aware of STIs prevention. Also, $50.7 \%$ and $21.3 \%$ of those respondents who were aware of STIs prevention identified sexual abstinence and the use of protective gears as measures to overcome STIs. The remaining $12 \%$ identified being faithful to one partner, having one partner, avoid unfaithful friends, self-respect, education on STIs and health testing as ways of STIs prevention.

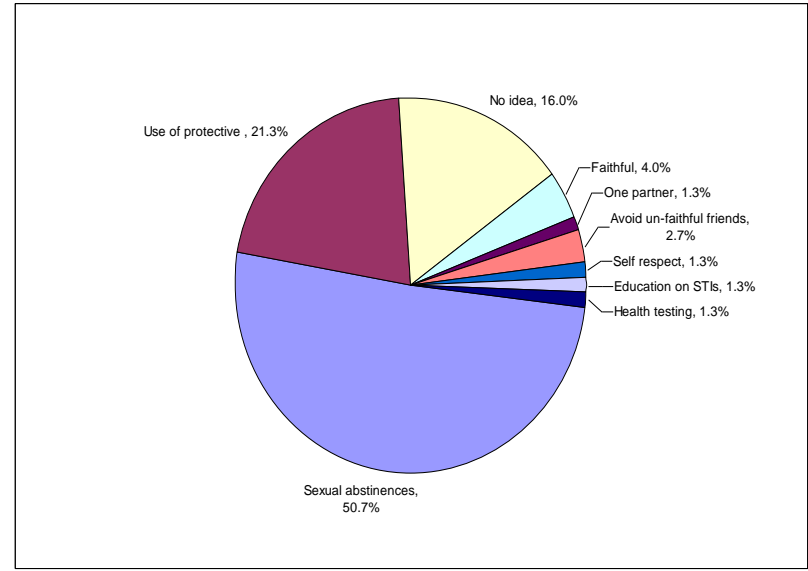

This study is in line with findings from other studies (UNESCO, 2009; WHO, 2013) which reported similar methods /approaches towards STIs prevention.

\subsection{Awareness on methods of controlling early preg- nancies}

The results revealed that $86.7 \%$ of the respondents were aware of the methods of controlling early pregnancies, while $13.3 \%$ of the respondents were not aware of methods to control early pregnancies. Table 2 reveals that $66.6 \%$ of the respondents who live with both parents were aware of the methods to control early pregnancies compared to $17.3 \%$ of the respondents who live with single parents. Also, $2.6 \%$ of the respondents who do not live with both parents were aware of the methods to control early pregnancies. Furthermore, $13.3 \%$ of the respondents who live with parents, single parent and those who do not live with parents were not aware of the methods to control early pregnancies.

Table 2: Awareness on Method of Controlling Early Pregnancies by Family Type

\begin{tabular}{|c|c|c|c|c|}
\hline & \multirow[b]{2}{*}{ Secondary school } & \multicolumn{2}{|c|}{$\begin{array}{l}\text { Awareness on methods to } \\
\text { control early pregnancies }\end{array}$} & \multirow[t]{2}{*}{ Total } \\
\hline & & Yes & No & \\
\hline \multirow{3}{*}{$\begin{array}{l}\text { Family type of } \\
\text { the respondent }\end{array}$} & Single parent & 13 & 1 & 14 \\
\hline & Both parents & 50 & 7 & 57 \\
\hline & $\begin{array}{l}\text { Do not leave with } \\
\text { parents }\end{array}$ & 2 & 2 & 4 \\
\hline Total & & 65 & 10 & 75 \\
\hline
\end{tabular}

\subsection{Students' engagement in sexual intercourse}

The results in Table 3 show that $74.7 \%$ of the respondents have had engaged themselves in sexual intercourse, while $25.3 \%$ of the respondents have never engaged themselves in sexual intercourse. Other studies (Resnick, 1997; Asrat, 2014) are also confirming incidences of secondary school students becoming sexually active at an increasing earlier age.

The results further reveal that $72 \%$ of the respondents who live with both parents have been engaging themselves with sexual intercourse (Table 6) whereas $25.3 \%$ of the respondents who live with single parent have engaged in sexual intercourse. Also $2.6 \%$ of the respondents who do not live with their parents have engaged in sexual intercourse. Furthermore, $12 \%$ of the respondents who live with parents and $16 \%$ of the respondents who live with single parent have not engaged in sexual intercourse. Also, 2.6\% of the respondents who do not live with parents have not engaged in sexual intercourse. The findings contradict with other findings on the role of parental marital status on adolescent sexual activity. For instance, Moore, et. al. (1995) asserted that adolescents, particularly females, living with one parent are more likely to engage themselves in early sexual behaviours. Furthermore, Day (1992) found out that the early onset of first intercourse has mostly been 
related to living with a single parent, moderately related to living with stepparents, and least related to living with biological parents However, this may be due to a decrease in the number of parents available to monitor, instead of simply a result of family structure alone.

Table 3: Students' Engagement in Sexual Intercourse by Family Type

\begin{tabular}{lllll}
\hline & & \multicolumn{3}{l}{ If has ever committed } \\
& Family type & Yes & No & Total \\
\hline & Single parent & 19 & 9 & 28 \\
Family type of & Both parents & 35 & 12 & 47 \\
the respondent & $\begin{array}{l}\text { Do not leave with } \\
\text { parents }\end{array}$ & 2 & 2 & 4 \\
Total & 56 & 19 & 75 \\
\hline
\end{tabular}

\subsection{Respondents' awareness on the effects of early pregnancies by family type}

The results show that $76 \%$ of the respondents who live with both parents are aware of the effects of early pregnancies (Table 7) and $18.6 \%$ of the respondents who live with single parent are aware of the effects of early pregnancies. Also, $5.3 \%$ of the respondents do not live with parents are aware of the method of early pregnancies. Furthermore, $29.3 \%$ of those who live with parents who understands the effects of early pregnancies mentioned expelled from school, death due to maternal complications (24\%), difficulties during giving birth $(2.6 \%)$, destruction of reproductive organs(2.6\%), acquire STIs (1.3\%), expansion of vaginal canal $(1.3 \%)$, life distortion (1.3\%), poor health of mother/child (1.3\%), birth of immature child (1.3\%), excessive bleeding (1.3\%), street children (1.3\%) and responsibilities while young (1.3\%).

\begin{tabular}{|c|c|c|c|c|}
\hline \multirow[b]{2}{*}{ Effects of early pregnancies } & \multicolumn{3}{|c|}{ Family type of the respondent } & \multirow{2}{*}{$\stackrel{\overrightarrow{0}}{ٍ}$} \\
\hline & $\begin{array}{l}\text { Single } \\
\text { parent }\end{array}$ & $\begin{array}{l}\text { Both } \\
\text { parents }\end{array}$ & $\begin{array}{l}\text { Do not } \\
\text { leave with } \\
\text { parents }\end{array}$ & \\
\hline Difficulties during giving birth & 1 & 2 & 0 & 3 \\
\hline Expelled from school & 4 & 22 & 3 & 29 \\
\hline $\begin{array}{l}\text { Deaths due to maternal compli- } \\
\text { cations }\end{array}$ & 5 & 18 & 1 & 24 \\
\hline Acquiring STIs & 1 & 1 & 0 & 2 \\
\hline Expansion of vaginal canal & 0 & 1 & 0 & 1 \\
\hline No idea & 1 & 4 & 0 & 5 \\
\hline Life distortion & 0 & 1 & 0 & 1 \\
\hline Poor health of child and mother & 0 & 1 & 0 & 1 \\
\hline Destructed reproductive organs & 0 & 2 & 0 & 2 \\
\hline Birth of immature child & 0 & 1 & 0 & 1 \\
\hline Excessive bleeding & 1 & 1 & 0 & 2 \\
\hline Abandoned by parents & 1 & 0 & 0 & 1 \\
\hline Increased street children & 0 & 1 & 0 & 1 \\
\hline $\begin{array}{l}\text { Forced to engage in responsibili- } \\
\text { ties while still young }\end{array}$ & 0 & 1 & 0 & 1 \\
\hline May lead to abortion & 0 & 1 & 0 & 1 \\
\hline otal & 14 & 57 & 4 & 75 \\
\hline
\end{tabular}

The identified effects of early pregnancy in Table 4 are similar to what Coley and Chase-Lansdale, (1998) and Jorgensen, (1993) have identified in their studies, which include; the likelihood of mothers to experience poor physical and mental health, educational attainment, employment and income, and a greater level of financial dependence and poverty than their non-childbearing peers. In addition, compared to children of older mothers, the children of teen mothers are more likely to experience poor health, cognitive ability, academic achievement, and social behavioral outcomes.

\subsection{Use of protective gears during sexual intercourse}

The results show that $82.7 \%$ of the respondents have never used protective gears during their last sexual intercourse, whereas $17.3 \%$ of the respondents have used such protective gears. A similar trend is reported in a study by Kessy (1996) on youth failure to practice safe sex and has linked it to how it contributes to the Sexual Transmitted Diseases (STDs) prevalence.

\section{Ethical considerations}

Research is a political activity which entails the exercise of power by the researcher on one side and the participant on the other (Bessants and Watts, 2007). This by itself calls for a need for ensuring that research processes or outcomes will not harm the participants by any means by failing to safeguard their dignity, rights, safety and well-being. To that effect, this study had to abide by ethical procedures and considerations.

In order to avoid any impediment to the research process an attempt was made by the researcher to clarify the purpose of the study to the local government officials and school leaders. This acted as one way to value the local leadership and authority. Participation in this study was voluntary. The researcher had to obtain the verbal informed consent from the participants. The participants were assured of their anonymity in that none of the information from them will be attributed to their names.

\section{Conclusion}

Much as Sexual health knowledge and attitudes could assist to reduce the risks of infected with STIs, but it remains an important aspect in determining the involvement of the youth in sexual intercourse. To have in place effective STIs prevention, this knowledge remains very crucial to the youth all over the world. This study has had a number of limitation including small sample size in terms of both the number of respondents and the schools covered. A study of this nature can be conducted involving a larger sample to solicit wider findings. Further studies could also think of a different methodology to avoid getting convenient responses from the respondents as some of the questions asked were very sensitive.

\section{Acknowledgement}

We feel indebted to academic members of staff at then Development Studies Institute of the Sokoine University of Agriculture for their comments on this manuscript, grateful to our respondents and the local Education Authorities in Morogoro Municipality and at the respective secondary schools for providing permit to conduct this study.

\section{References}

[1] AlQuaiz AM, Kazi A \& Al Muneef M (2013), Determinants of sexual health knowledge in adolescent girls in schools of RiyadhSaudi Arabia: a cross sectional study. BMC Women's Health 13:19. https://doi.org/10.1186/1472-6874-13-19.

[2] Abubakar F (2009), More is needed to curb students drop out and early pregnancies. [www.entribune.com/articles] Site visited on $13 / 12 / 2015$

[3] Asrat A (2014), Assessment of Sexual Risk Behaviours of InSchool Youth: Effect of Living Arrangement of Students; West Gojam Zone, Amhara Regional State, Ethiopia. American Journal of Health Research. 2(2)78-83. https://doi.org/10.11648/i.ajhr.20140202.18

[4] Bessant, J., Watts, R., 2007. Ethic and Sociology, in: Sociology Australia. Allen and Unwin, New South Wales.

[5] Bonell C, Allen E, Strange V, Oakley A, Copas A, Johnson A, \& Stephenson J (2006), Influence of family type and parenting behaviours on teenage sexual behaviour and conceptions. Journal of Epi- 
demiology Community Health. 60(6):502-6. https://doi.org/10.1136/jech.2005.042838.

[6] Botting B, Rosato, M \&Wood R (1998). Teenage mothers and the health of their children. Population Trends;93:19-28.

[7] Centre for Reproductive Rights (2008). An International Human Right: Sexuality Education for Adolescents in Schools. New York: Centre for Reproductive Rights.

[8] Coley RL \& Chase-Lansdale PL (1998), Adolescent pregnancy and parenthood. American Psychologist, 53, 152-166. https://doi.org/10.1037/0003-066X.53.2.152.

[9] Day RD (1992), the transition to first intercourse among racially and culturally diverse youth. Journal of Marriage and Family, 54, 749-762. https://doi.org/10.2307/353158

[10] Glasier A, Gülmezoglu AM, Schmid GP, Schmid GP, Moreno CG $\&$ Van. Look (2003), Sexual and reproductive health: a matter of life and death. Lancet. 2006; 368(9547):1595-1607. https://doi.org/10.1016/S0140-6736(06)69478-6.

[11] Herman L, Ovuga E, Mshilla M, Ojara S, Kimbugwe G, Adrawa AP \& Mahuro N (2013), Knowledge, Perceptions and Acceptability to Strengthening Adolescents' Sexual and Reproductive Health Education amongst Secondary Schools in Gulu District. World Academy of Science Engineering and Technology 2013 Jul 25; 7(7) 1787-1802.

[12] Ikamba LM \& Ouedraogo B (2003), High-risk sexual behaviour: knowledge, attitudes and practice among youth at Kichangani ward, Tanga, Tanzania. Action Research Reports 018.

[13] Jorgensen SR (1993), Pregnancy and parenting. In T. P. Gullota, G R. Adams, \& R. Montemayer (Eds.), Advances in adolescent development (Vol. 5) (pp. 103-140). Newbury Park, CA: Sage.

[14] Kessy A (1996), Prevalence and risk factors for HIV and other STDs among youth in Moshi Rural District. M.A. Dissertation, University of Dar es Salaam

[15] Klepp K, Ndeki S, Seha A, Hannan P, Lyimo B \& Msuya M (1994a), AIDS education for primary school children in Tanzania: An evaluation study. AIDS, 8(8), 1157-1162. https://doi.org/10.1097/00002030-199408000-00019.

[16] Klepp KI, Ndeki SS, Thuen F, Leshabari MT \& Seha AM (1994b), Predictors of high risk behaviour among Tanzania school youth. AIDS Care. 62:218-224.

[17] Klepp KI, Mnyika KS, Kingori NO, Leshabari MT \& Kissila PE (2004), AIDS knowledge and risk perception in urban and rural communities in Arusha region, Tanzania. East African Journal of Public Health 1:40

[18] Leshabari, MT (1988), Factors influencing school adolescent fertility behaviour in Dar es Salaam. PhD Dissertation, Johns Hopkins University. 102pp.

[19] Manlove J (1997), early motherhood in an intergenerational perspective: the experiences of a British cohort. Journal of Marriage and Family;59:263-79. https://doi.org/10.2307/353469.

[20] Masatu M, Kazaura R, Ndeki S \& Mwampambe R (2009), Predictors of Risky Sexual Behavior among Adolescents in Tanzania. [http://www.ncbi.nlm.nih.gov/pubmed/17690974?dopt=AbstractPlu s\&holding $=f 1000, \mathrm{f} 1000 \mathrm{~m}$, isrctn] site visited on $27 / 12 / 2010$ https://doi.org/10.1007/s10461-007-9292-x.

[21] Moore KA, Morrison DR \& Glei DA (1995), Welfare and adolescent sex: The effects of family history benefit levels, and community context. Journal of Family and Economic Issues, 16, 207-237. https://doi.org/10.1007/BF02353709.

[22] Muhanga MI \& Malungo JRS (2017a), the What, why and how of Health Literacy: A Systematic Review of Literature. International Journal of Health, 5(2)107-114. https://doi.org/10.14419/ijh.v5i2.7745.

[23] Muhanga MI \& Malungo JRS (2017b), Does Attitude Associate, Correlate, Or Cause Behaviour? An Assessment Of Attitude Towards Health Behaviour Under One Health Approach In Morogoro, Tanzania, International Journal of Advanced Research and Publications (IJARP), http://www.ijarp.org/online-paperspublishing/sep2017.html, Volume 1 - Issue 3, September 2017 Edition, 82-91 \#ijarp

[24] Mwananzila L (2009), Tanzania men can help to stop school pregnancies [http://dailynews.co.tz/feature/?n=6102] Site visited on $13 / 12 / 2010$

[25] Resnick MD (1997), Protecting adolescents from harm: findings from the national longitudinal study on adolescent health. JAMA (278) 823-832. https://doi.org/10.1001/jama.1997.03550100049038.

[26] Chacko S, Kipp W, Laing L \& Kabagambe G (2007), Knowledge of and Perceptions about Sexually Transmitted Diseases and Pregnancy: A Qualitative Study among Adolescent Students in Uganda. Journal of Health, Population and Nutrition; 25(3): 319-327.
[27] UN OHCHR (2003), Convention on the rights of the Child, General Comment 3 , supra note 23 , para. 16 . Geneva: UN OHCHR

[28] UNAIDS (1997), Impact of HIV and Sexual Health on the Sexual Behaviour of Young People: A Review Update 27. Geneva: UNAIDS.

[29] UNAIDS (2006), Scaling up access to HIV prevention, treatment, care and support. The next steps. Geneva: UNAIDS

[30] UNAIDS (2007), Practical Guidelines for Intensifying HIV Prevention: Towards Universal Access [data.unaids.org/pub/manual/2007...] Site visited on 10/12/2010

[31] UNAIDS (2008), Report on the Global AIDS Epidemic. Geneva: UNAIDS

[32] UNESCO (2008), School-centred HIV and AIDS Care and Support in Southern Africa: Technical Consultation Report, 22-24 May 2008, Gaborone, Botswana. Paris, UNESCO.

[33] UNESCO (2005). Reducing HIV/AIDS Vulnerability among Students in the School Setting: A Teacher Training Manual. Bangkok: UNESCO. [unesdoc.unesco.org/../138910e.pdf] Site visited on $10 / 12 / 2010$

[34] UNESCO (2009). International Guidelines on Sexuality Education: An evidence informed approach to effective sex, relationships and HIV/STI education. Paris: UNESCO

[35] URT (2004). Secondary Education Development Plan [www.moe.tz/pdf/SEDP FINAL.pdf] Site visited on 27/12/2014

[36] URT (2006). National Population Policy [www.tanzania.go.tz/1pdf/idadiEng.pdf] Site visited on 27/12/2014

[37] WHO (2013), Sexually Transmitted Infections (STIs). Department of Reproductive Health and Research, WHO, Geneva, Switzerland. http://apps.who.int/iris/bitstream/10665/82207/1/WHO_RHR_13.0 2 eng.pdf. Site accessed on 26/09/2017.

[38] UNESCO (2009), International Technical Guidance on Sexuality Education: An evidence-informed approach for schools, teachers and health educators. Vol.I The rationale for sexuality education. http://unesdoc.unesco.org/images/0018/001832/183281e.pdf. 